\title{
Half Oaks, Half Willows: Degree, Not Direction, of Handedness Underlies Both Stable Prevalence in the Human Population and Species-Beneficial Variations in Cognitive Flexibility
}

\author{
Stephen D. Christman ${ }^{1}$ Eric C. Prichard ${ }^{1}$
}

Published online: 9 March 2016

(C) Springer International Publishing 2016

\begin{abstract}
A classification of humans into a near 50-50 split of inconsistent- versus consistent-handers is more consistent with behavioral, genetic, and evolutionary considerations than the traditional classification of $90 \%$ right-handed and $10 \%$ left-handed. In addition, inconsistent- versus consistenthandedness is associated with more flexible versus rigid cognitive styles, respectively, and it is argued that this heterogeneity of cognitive styles provided by the inconsistent-handed "willows" versus the consistent-handed "oaks" gives human society a beneficial blend of adaptive flexibility and stability.
\end{abstract}

Keywords Handedness · Evolutionary psychology · Behavioral genetics · Individual differences · Cultural group selection

A persistent and perplexing question has long dogged researchers who study handedness. Why do left-handers exist? There are several ways to approach question. One approach is ontological: "how does handedness develop?" Another approach is phylogenetic: "how did handedness evolve?" Ontogeny and phylogeny are intertwined, and understanding one casts light on the other. The purpose of the present paper is to provide a novel approach to the phylogenetic question (although we hope it will also be useful to those interested in ontogeny). We will tackle it from two perspectives: first, arguing that degree, not direction, of hand preference is the

Stephen D. Christman

stephen.christman@utoledo.edu

1 Department of Psychology, University of Toledo, Toledo, OH 43606 , USA key dimension at play, and second, arguing that systemic, population-wide variations in cognitive flexibility as a function of degree of handedness may have proven evolutionarily adaptiveness to the human species overall.

A recent review of the literature investigating the evolution of handedness suggests that little progress has been made in determining how and why left-handedness evolved and why left-handers persist (Llauren et al. 2009). Approximately $90 \%$ of people are right-handed and a comparable number are leftlateralized for speech (Llauren et al. 2009; McGilchrist 2009), and this pattern of roughly nine right-handers for every lefthander has been stable in the human species for at least 500, 000 years (Frayer et al. 2012).

A central mystery regarding the evolution of handedness is the persistent minority status of left-handedness (e.g., Harris 2000). As Darwin noted, "modifications that are in no way beneficial cannot have been kept uniform through natural selection, though any which were injurious would have been thus eliminated" (p. 152, Darwin 1875/1868). Thus, if righthandedness conveyed an adaptive benefit relative to left-handedness, the percentage of right-handers should climb to 100 over time, and vice versa if left-handedness conveyed a benefit relative to right-handedness. The persistent population percentages of left- and right-handedness imply no overall benefit to either handedness type. This raises a problem with the stable, persistent nature of the left-handed minority: given the evidence for equivalent adaptiveness for left- and righthandedness, one would expect a certain "regression to the mean"-like drift towards a 50-50 equilibrium between the two in the overall population, but there is no evidence for this.

We propose a novel and simple explanation for this persistent mystery: the human population should not be thought of as consisting of about $90 \%$ right-handers and about $10 \%$ lefthanders, but rather as consisting of slightly over half of humans having a strong, consistent pattern of hand preference 
and slightly under half having a mixed, inconsistent pattern. This near 50-50 split (slightly favoring consistent-handers) is typically based on a simple median split of absolute value scores on a variant of the Edinburgh Handedness Inventory (Oldfield 1971). ${ }^{1}$ Our variant of the EHI is scored on a scale ranging from -100 (pure left-handedness) to +100 (pure righthandedness). The median of the absolute values is typically around +80 ; thus, to be classified as "consistent-handed," one must indicate exclusive or primary use of the same hand for most of or all ten activities listed on the inventory. At least two large-scale data sets indicate that using an absolute value of 80 as the cutoff for inconsistent-handers yields a roughly even split. Prichard et al. (2013) summarize data from 1595 participants. Overall, the data suggest that consistent and inconsistent-handedness is roughly evenly distributed among males and that consistent-handedness is more common among females. A factor analysis of the EHI variant described in the footnote looked at data from 987 right-handers (Christman et al. 2015). In this sample, approximately $51 \%$ were inconsistently handed, which conflicts with the pattern Prichard et al. (2013) reported. However, gender data was not available for all of the participants in the latter study and a slight imbalance in favor of consistent-handers is to be expected when the subject pool is predominantly or at least $50 \%$ female.

Dividing humans on the basis of the degree/strength, as opposed to direction, of preference for their dominant hand often has more predictive power than direction of handedness in many domains (Prichard et al. 2013). For example, a plethora of recent studies show that inconsistent-handers have an advantage, relative to consistent-handers, on tests of episodic memory retrieval (e.g., Alipour et al. 2012; Christman and Butler 2011; Christman and Propper 2001; Christman et al. 2006; Christman et al. 2004; Chu et al. 2012; Edlin et al. 2013; Lyle et al. 2012; Lyle et al. 2008; Parker and Dagnall 2010; Propper and Christman 2002, 2004; Propper et al. 2005). On the neuroanatomical and neurophysiological levels, inconsistent-handedness sometimes predicts greater callosal size (e.g., Luders et al. 2010) and greater resting right hemisphere activity as measured by alpha band activity (Propper et al. 2012). McDowell et al. (2015) did a large-scale study in which they looked at MRI data from 164 participants crossed for gender and consistency of handedness. While inconsistenthanders did not have significantly more callosal volume, they did show less global asymmetry, fewer regional asymmetries, and greater right hemisphere gyrification than consistent-handers.

\footnotetext{
${ }^{1}$ A very important point raised by Edlin et al. (2015) is that many versions of handedness inventories referring to themselves as the "EHI" exist. The variant typically used by our lab differs slightly from the original. It is a 10-item scale which uses the items writing, drawing, spoon, jars, toothbrush, throwing, comb, scissors, knife, and match. Furthermore, it consists of five response options: Always left, usually left, no preference, usually right, and always right.
}

The memory findings, which have been shown to hold even when consistency and direction of handedness are crossed (Lyle et al. 2012), are consistent with theories which posit that the right hemisphere plays an important role in the retrieval of episodic memory (Habib et al. 2003). The neurophysiological findings suggest systematic anatomical differences that may result in enhanced functional access to right hemisphere processing for inconsistent-handers. It is important to be as clear as possible about what is meant by "functional access" to the right hemisphere. We believe the evidence suggests that the right hemisphere plays a relatively greater role in the cognitive processes of inconsistently handed individuals than in the cognitive processes of consistently handed individuals. This does not mean that inconsistenthanders are "right brained" nor that the right hemisphere plays no role in the cognition of consistent-handers. Nor does it necessarily mean that there is more callosally mediated transfer between the hemispheres in inconsistent-handers. It is quite possible that the more symmetrical left hemisphere of inconsistent-handers can more easily inhibit the right hemisphere than can the left hemisphere of consistent-handers (e.g., Davidson and Tremblay 2013). This in itself could increase the role of the right hemisphere in cognitive functions. While much work needs to be done to parse out the underlying mechanisms, we believe that behavioral evidence and neurophysiological evidence are most parsimoniously synthesized by a model which posits that the reduced hemispheric asymmetries of inconsistent-handers mediate an increased relative role of the right hemisphere in higher level processing.

We therefore argue that consistency and degree, not direction, of handedness is a fundamental dimension on which humans differ both behaviorally and physiologically. That is not to say that direction of handedness is not an important variable. In fact, it seems there are domains in which direction is important and in which direction and degree interact. For example, Lyle et al. (2013) found that inconsistent-handedness predicted reduced anxiety, but only among right-handers. Hardie and Wright (2014) found that direction of handedness effects in behavioral inhibition and activation scores were modulated by direction of handedness. However, when both direction and degree of handedness are taken into account, it is often the degree of handedness that appears to account for significant differences among humans.

So what is the nature of the relation between degree and direction of handedness? First, it is important to note that these two dimensions are not independent: about $80 \%$ of lefthanders are inconsistent-handed, while about $60 \%$ of righthanders are consistent-handed (Prichard et al. 2013). Thus, comparisons between left- and right-handers can be viewed as noisy comparisons between inconsistent- and consistenthanders. Second, genetic models of handedness (e.g., Annett 2002; McManus 1991; McManus et al. 2013) posit the influence of two factors: a genetic factor that predisposes one to 
right-handedness and an environmental factor in which handedness is determined by chance environmental influences. We therefore argue that the $10 \%$ of the population who are lefthanded for writing are simply people for whom the chance environmental factors have routinely lined up so as to favor left-handedness. It is also possible that left-handers are people for whom epigenetic factors have altered gene expression. This would allow for direction to still be an important variable without forcing researchers to posit the existence of an extra gene. Leach et al. (2014) found that methylation of LRRTM1 was associated with inconsistent-handedness. Risk alleles of a single-nucleotide polymorphism (SNP) in LRRTM1 are also associated with schizotypy and schizophrenia. This suggests that epigenetic factors are at play in the development of consistency of hand preference, but epigenetic factors could conceivably affect direction as well.

Relatedly, it is important to note that none of the extant genetic models of handedness hypothesize the explicit existence of "left-handedness" genes; both Annett's and McManus' models posit a continuum between strong righthandedness and "random" handedness. It is also important to note that the emerging genetic evidence suggests that the degree handedness is related to multiple genes and lateralization. For example, Arning et al. (2013) found that a variable number tandem repeat polymorphism on gene PCSK6 was associated with degree of handedness, but not direction of handedness. According to the authors, PCSK6 is known to play a key role in left-right asymmetry and to be a target of transcription factor FOXP2, which is associated in the development of speech. Multiple studies (Arning et al. 2015; Hampson and Sankar 2012) found that inconsistently handed men have longer CAG repeats on the human androgen receptor gene (AR), which is found on the $\mathrm{X}$ chromosome, than either strong leftor right-handed males. As men have only one X chromosome, there is no $\mathrm{X}$ inactivation which can cancel or attenuate the effect of an X-linked gene in men. This might partially explain why inconsistent-handedness is more common among men.

With genetic models and specific genetic evidence suggesting an important role for genes associated with consistency of handedness, the question of the evolution of human handedness can be reframed. Evolutionary explanations of handedness such as the fighting hypothesis (e.g., Raymond et al. 1996) often focus on potential selective tradeoffs of left-handedness. For example, Raymond et al. (1996) suggest that lefthanders may have had an advantage in combat and cite lefthanded advantages in certain sports as evidence. However, if there are genes associated with consistency of handedness, but not "left handed genes" per se, then it becomes difficult to explain the persistence of left-handedness in terms of the selective tradeoffs of left-handedness alone. Evolution can be conceptualized as a population level change in allele frequencies and presumably two individuals could have the same genotype but different handedness. The fact that the handedness concordance rate among identical twins is less than $100 \%$ (e.g., McManus 1980) suggests that this is so. Any theory of evolution has to explain the stability of allele frequencies. Since left-handedness is just one potential phenotypic expression of an individual who has genes predisposing them to inconsistent-handedness, we suggest that evolutionary explanations should be expanded to include selective tradeoffs associated with traits related to consistency of handedness.

The second part of this paper now addresses the adaptive benefits of handedness variations in the population to the survivability of the overall human population. While we argue that inconsistent-handers possess neither a quantitative advantage nor disadvantage relative to consistent-handers, we argue that qualitative differences between the cognitive styles of inconsistent- and consistent-handers proffer an adaptive benefit to the human species as a whole.

The story begins with an early handedness study which found that consistent-handers were more likely to endorse literal, young-earth creationist beliefs (Niebauer et al. 2004). At first glance, such a finding makes little sense. Why would one's consistency of handedness predict greater likelihood of holding creationist beliefs? The answer may lie with individual differences in functional access to the right hemisphere. Ramachandran's (1995) work with patients suffering from anosognosia resulting from right hemisphere damage led him to hypothesize that the right hemisphere is essential for belief updating. These patients frequently suffer from left-side hemineglect. Furthermore, they often suffer from bizarre delusions such as denial of their condition, and the belief that their paralyzed left limbs belong to other people. Ramachandran proposed that the right hemisphere plays a role in belief updating, acting as a devil's advocate prompting the left hemisphere, which maintains schemas, to change its beliefs. The right hemisphere pays attention to context and the whole, while the left hemisphere parses, categorizes, and organizes (McGilchrist 2009). If a schema is thought of as an associative network of beliefs, facts, and cognitive scripts that are activated when one becomes aware of a concept, then it makes sense that the schema would be part of left hemispherecontrolled categorization. The right hemisphere's job may then be editing and updating this network when new evidence becomes available. Consequently, when the right hemisphere is damaged, patients cannot edit their beliefs about their physical conditions.

Might an increased relative role of the right hemisphere in inconsistent-handers predispose them to update beliefs more frequently and exhibit greater cognitive flexibility? The finding regarding handedness differences in belief in the theory of evolution is tantalizing and is consistent with developmental evidence that children go through a systematic progression of belief updating as they form and revise beliefs about the origins of species (e.g., Evans 2000). Additional findings looking at handedness and belief updating have been even more 
revealing. Christman et al. (2008) found that inconsistenthanders are more easily persuaded in a popular persuasion paradigm from social psychology and more gullible and susceptible to the Barnum effect. Other findings suggest that individuals with inconsistent-handedness are more prone to magical ideation of the type indicative of schizotypal behavior (Barnett and Corballis 2002). Inconsistent-handers are also able to more readily and appropriately update their right parietal-based body image representations (Christman et al. 2007; Niebauer et al. 2002). Shobe et al. (2009) reported that inconsistent-handers score higher on measures of right hemisphere-based divergent thinking (e.g., Bowden and Jung-Beeman 2003) as measured by the alternate uses task.

Inconsistent-handedness is associated with greater "openearedness," referring to one's openness to novel musical genres (Christman 2013). Inconsistent-handers are also better able to update interpretations of ambiguous figures (Christman et al. 2009) and exhibit greater flexibility in dealing with semantic representations (Sontam et al. 2009; Sontam and Christman 2012). Inconsistent-handers also display greater flexibility in updating beliefs in a variety of decisionmaking paradigms (Jasper et al. 2008; Jasper and Christman 2005; Jasper et al. 2009; Westfall et al. 2012).

Finally, handedness differences at more global levels of personality, consistent with increased cognitive flexibility, have been reported. Grimshaw and colleagues have reported evidence suggestive of greater openness to experience and introversion in inconsistent-handers (Bryson et al. 2009; Grimshaw and Wilson 2013). Christman (2013) found that inconsistent-handedness predicted greater sensation seeking, decreased feelings of disgust, and decreased right wing authoritarianism. Lyle and Grillo (2014) discovered that consistent-handers were more likely to endorse conservative ideologies, had more negative attitudes towards out-groups, and scored higher on an instrument designed to measure one's proclivity to submit to authority. It should be noted that this is hardly the first time that markers of neurophysiological processes have been used to investigate differences in political orientation. Previous research has shown that the anterior cingulate cortex (ACC) has more gray matter and more conflictrelated activity in politically liberal subjects (Amodio et al. 2007; Kanai et al. 2011). While the specific brain asymmetries involved are different, both the handedness findings and the neurophysiological findings investigating differences in ACC activity suggest that individual differences in belief updating and openness may have both neuropsychological substrates and consequences at the level of political activity.

More circumstantial evidence in line with the idea that more politically liberal individuals may experience more conflict-related activity or may have more access to the right hemisphere can be found in studies of the neurocorrelates of mood. Research showing that damage to the right hemisphere often leads to an indifferent emotional reaction, while damage to the left hemisphere leads to a "catastrophic" emotional reaction, led some researchers to posit that the right versus left hemisphere is the seat for negative/withdrawal-related versus positive/approach-related emotions, respectively (e.g., Davidson 2000). While likely an oversimplification, depression is associated with a hyperactive right hemisphere (Hecht 2010). Polls showing that liberals report being less happy than conservatives (e.g., Taylor et al. 2006) are rarely explained in neurobiological terms. However, it is a finding that is consistent with a theory which suggests that liberal attitudes are associated with greater access to the right hemisphere.

To summarize, inconsistent-handedness is associated with increased cognitive flexibility and openness to environmental feedback, while consistent-handedness is associated with greater stability of beliefs and mental representations and with decreased gullibility. Although speculative, we present here a tentative hypothesis which we believe can be investigated and incorporated into evolutionary research. We suggest that the true polymorphism of interest is not left- versus right-handedness, but consistent- versus inconsistent-handedness. More to the point, we propose the true polymorphism lies in different schemes for brain organization which lead to both differences in consistency of hand preference and, more importantly, differences in overall thinking styles. Critically, if heterogeneity in cognitive styles gave early human groups a significant advantage, then heterogeneous groups would have outlasted groups with less variability.

The view proposed here is that population-level heterogeneity and diversity in thinking styles is an adaptive advantage that humans possess as a species and is manifested in a 50-50 split in the human population between inconsistent- and consistent-handers. The basic idea, to be expanded below, is that (i) cognitive flexibility versus rigidity convey complementary adaptive benefits and, since cognitive flexibility and rigidity are mutually exclusive, (ii) they cannot be manifested simultaneously in the same individual and thus need to be distributed across different individuals (i.e., inconsistent- and consistent-handers) in the population.

An engineering analogy is appropriate here: in order to build a strong and enduring structure, one needs two mutually exclusive elements: rigidity for strength and stability and flexibility for adapting to dynamic forces such as wind shear, ground tremors, and load bearing. Think of skyscrapers in earthquake-prone regions, or the crumple zones in cars. So, in order to build a strong and enduring society, perhaps it is beneficial to the society as a whole to have some members contribute primarily to its stability and others contributing primarily to its flexibility and change. It is also worth noting that in nature, it is not unheard of for scientists to observe species with polymorphisms that give specific individuals distinct advantages and disadvantages, but which make the entire species more robust. For example, Geoffroy's marmosets may have either trichromatic or dichromatic vision (Caine and 
Mundy 2000). Trichromats have a foraging advantage for low food with colors that have relatively low electromagnetic frequencies (e.g., red and orange), but dichromats are not disadvantaged under conditions of color camouflage (Caine and Mundy 2000; Caine et al. 2003). Cole and Quinn (2014) were able to classify two personality types among female great tits. They placed novel objects on the nests of the birds who had recently laid eggs. Birds with bolder exploratory behaviors were found to more quickly return to the nest after the appearance of a novel object. It was hypothesized that bold birds may "prioritize" short-term reproductive investment, whereas shy birds "prioritize" survival. Bold birds may better protect their nests, but at the cost of higher personal risk. Shy birds may take fewer personal risks, but may live to lay another clutch.

The basic idea here is that inconsistent- and consistenthanders fill different sociocognitive niches (as opposed to niches related to food acquisition a la marmoset or nesting behavior a la great tits), with inconsistent-handers serving as flexible "willows," open to entertaining new ideas and beliefs, and consistent-handers serving as more rigid "oaks," tending to stick with the tried and true. As evidence shows that inconsistent-handers report greater willingness to engage in risky recreational activities (Christman et al. 2007) and more sensation-seeking behaviors (Christman 2014), their cognitive flexibility and risk-taking behaviors may have combined to provide a distinctive selective tradeoff relative to rigidity of consistent-handers in early evolutionary environments.

In early evolutionary environments, our distant ancestors routinely faced situations, such as food scarcity or encounters with out-groups, which would have faced one's in-group with potentially life or death decisions. Additionally, research on changes in the traditional diets of indigenous groups shows that hunter gathers whose diets have the most diversity not only receive a better balance of dietary nutrients from the traditional diet but often see a decline in health with the introduction of a more homogenous diet (Kuhnlein and Receveur 1996). If food became scarce, the more flexible inconsistenthanders might have been more willing to try new food sources. They may have also been more willing to try new food sources which added to the diversity and hence the nutritional value of their traditional diets. When the "willow" food testers turned out fine after sampling a new food source, it would then signal to the rest of the group that a safe new food source was discovered. The whole group would have benefited. Conversely, if the food turned out to be poisonous, then the "willows" would pay a price but the "anchors" would be spared. However, more conservative groups that had no "willows" would have also paid a price in times of scarcity or in terms of nutrient deficits due to their reluctance to sample new food sources. Over the long run, groups that had a balance of food testers and non-testers would have had the best outcomes. Groups with too many "willows" would risk being wiped out by poisoning, while groups with too many "oaks" would risk missing out on potentially valuable new sources of food.

A similar argument holds for in-group/out-group interactions. When a group of hunter gatherers encountered a new band of people, they faced several possible outcomes. If the other band was friendly, then new mates, new technologies, and more complex forms of cooperation may have become available. If the group was unfriendly or carried new pathogens, disaster lurked. For example, Chagnon (1988) and Lizot (1994) documented complex conflict dynamics among the Yanomamo tribes of Brazil. Chagnon (1988) indicated that the most fierce village he documented had one of the highest rates of interrelatedness among villages. If rate of interrelatedness is used as a proxy for group cohesion, then this indicates that this particular village intermarried more than average and allowed fewer outer village influences in than average. The benefit was that the group had a reputation for viciously avenging the death of kin and sexual assaults on women of the village. On the other hands, groups with lower rates of interrelatedness tended to be militarily weaker and were frequent targets of raids which often included theft, rape, and the capture of women. However, Lizot (1994) reported that Yanomamo men with the most violent reputations were also frequent victims of attack (because it removed a menace and raised the status of the raiding party) and that these men rarely died natural deaths. Furthermore, he documented the existence of other complex intervillage forms of cooperation, conflict resolution, and resources allocation that often allowed mutually beneficial interactions between the villages. As such, it seems that being too insular or too ready to accept outside influences both resulted villages becoming targets for attack.

At a more sociological level, a diversity of thinking styles might be a protective factor against maladaptive social change. Just as having a certain proportion of a group that is immune to a pathogen can allow the group to survive an outbreak of a disease, having a certain group immune to excessive authoritarianism can doom repressive regimes in the long run and having a group that is skeptical of new ideas can temper the spread of new ideas and beliefs which may ultimately be harmful. For example, an authoritarian person who does not update their beliefs may be more likely to support a fascist regime in one era and place, but the very same person might be among those most suspicious of and resistant to fascism when it is a new idea introduced to a society and era in which people are raised to value democratic ideals. Another way of putting this is what we term the Berkeley-Birch Hypothesis. In the 1960s, much of the Western World saw an era of new ideas. Out of the 1960s came positive social change like the Civil Rights Movement, the Feminist Movement, and some healthier attitudes towards sexuality. The dark side of this openness was a rise in STI's, drug 
Table 1 Handedness prevalence percentages for the 14 countries reported by Raymond and Pontier (2004), along with those countries' respective rankings on the Human Development Index and World Happiness Report

\begin{tabular}{llll}
\hline & $\begin{array}{l}\text { Percentage of } \\
\text { left-handers }\end{array}$ & $\begin{array}{c}\text { Human Development } \\
\text { Index ranking }\end{array}$ & $\begin{array}{c}\text { World Happiness } \\
\text { Report ranking }\end{array}$ \\
Japan & 6.4 & 20 & 46 \\
Brazil & 7.6 & 75 & 16 \\
Sudan & 8.8 & 167 & 118 \\
UK & 10.7 & 14 & 21 \\
Algeria & 11.1 & 83 & 68 \\
USA & 12.6 & 8 & 14 \\
Canada & 15.1 & 9 & 5 \\
Nigeria & 16 & 152 & 78 \\
Australia & 16.9 & 2 & 10 \\
Mexico & 18.3 & 74 & 15 \\
Cote d'Ivoire & 19.6 & 172 & 151 \\
Spain & 21 & 26 & 36 \\
France & 23.2 & 22 & 29 \\
& Average percentage & Average ranking & Average ranking \\
Bottom 4 & 8.38 & 69.00 & 50.25 \\
Middle 5 & 14.34 & 50.80 & 35.00 \\
Top 4 & 20.53 & 73.50 & 57.75 \\
\hline
\end{tabular}

addiction, and political radicalism that could take violent forms. At the same time, John Birchers feared communist infiltration to the point of irrationality. Certainly the Red Scare is an unfortunate period in US history. However, the Cold War era was not without espionage, propaganda, and attempts by both Eastern and Western powers to subvert one another. As such, the pull of anti-communist organizations (although they were often extreme and guilty of excesses) may have forced political and military leaders to be more vigilant. The net result was a society that made progress on social issues and resisted communism. ${ }^{2}$ If our society had been too tilted in favor of the inconsistent-handed "willows, " then we might have gone off the deep end of excessive drug use, sexual promiscuity, and blind mistrust of authority. Alternatively, if our society had been too tilted in favor of the consistent-handed "oaks," then, metaphorically, women would still be barefoot in the kitchen and Rosa Parks would still be riding at the back of the bus.

As such, different thinking styles may serve to counterbalance each other and propagate civilization as a whole, even if individual groups within a society would be destructive given unfettered reign. To put it in more evolutionary terms, early human groups that lacked cognitive diversity were likely to be either killed off by the too-ready adoption of bad ideas or killed off by stagnation fueled by a reluctance to adopt new beliefs.

\footnotetext{
${ }^{2}$ For more information on the John Birch Society written for a general audience, see Mallon (2016). For reading on the intersection of the counter-culture, the cold war, and late twentieth century science, see Kaiser (2011).
}

It is possible that this sort of balance in thinking styles continues to operate in larger modern societies. For example, nonright-handers are overrepresented in the Northeastern USA, a region that traditionally votes for more liberal politicians, while right-handedness is relatively overrepresented in Southern and Plains states, regions that traditionally vote for more conservative politicians (McManus 2009). Together, these regions balance one another, preventing the USA from drifting too far towards far-left socialism or far-right fascism. McManus also reports ethnicity differences, with lefthandedness being most prevalent among Whites, Blacks, and American Indians and less prevalent among Asians and Hispanics.

Evolutionary hypotheses are often subjected to the criticism that they are untestable and just so stories. We propose that our model generates questions which can be tested empirically. First and foremost, handedness can easily be incorporated as a variable into pre-existing evolutionary psychology paradigms. It is simply a matter of classifying individuals with validated handedness measures (see Edlin et al. 2015 for a primer on the issues involved in this process). Second, much work has already been done demonstrating that there are systematic differences between consistent- and inconsistenthanders on measures of openness and cognitive flexibility, which in turn predict socially complex behaviors such as political affiliation, social cooperation, social unrest, and change, and education.

The next step would involve the following question: can it be shown that diversity of thinking styles has adaptive fitness advantages for groups over cognitive homogeneity? This could be addressed in at least two ways. One would involve 
creating small groups in laboratory situations that are either heterogeneous or homogenous in handedness classification and cognitive flexibility/rigidity and examine whether the heterogeneous group are better at group processes and dynamics.

The second would involve possible cross-cultural comparisons between countries that vary in their population proportions of different handedness groups. Although geographical variations in degree of handedness have not yet been studied, variations in direction of handedness have, and, as noted above, direction of handedness can be considered a crude proxy for degree of handedness. Thus, countries with a smaller percentage of left-handers are likely to have a smaller percentage of inconsistent-handers and hence may display greater rigidity in social processes. Conversely, countries with higher percentages of left-handers are likely to have greater percentages of inconsistent-handers, leading to greater flexibility in social processes. For example, Perelle and Ehrman (1994) reported higher than average rates of left-handedness in France and Spain, normal rates in Nigeria and Australia, and lower than average rates in Mexico and Turkey. Similarly, Raymond and Pontier (2004) reported higher than average rates of left-handedness in Canada and the USA, normal rates in France and Australia, and lower than average rates in Japan and Sudan. It might be predicted that societies with more left/inconsistent-handers would be more volatile and unstable, while societies with more right/consistent-handers would be more rigid and authoritarian.

Tentative evidence for this idea can be found by looking at national measures of quality of life for the countries studied by Raymond and Pontier (2004). Specifically, we looked at the Human Development Index (HDI; United Nations Development Programme 2014) and World Happiness Report (WHR; Helliwell et al. 2015) rankings of the 14 countries for which Raymond and Pontier provided handedness prevalence estimates (for countries with more than one handedness prevalence estimate, the average percentage of left-handers was calculated). These data are presented in Table 1.

The four countries with the lowest rates $(<11 \%)$ of lefthandedness (Japan, Brazil, Sudan, and UK) had average rankings of 69 on the HDI and 50.25 on the WHR, and the four countries with the highest rates $(>18 \%)$ of left-handedness (Mexico, Ivory Coast, Spain, France) had average ranking of 73.5 on the HDI and 57.75 on the WHR. In contrast, the five countries with intermediate rates of handedness and, therefore, presumably the most balanced distribution of consistent- and inconsistent-handers (Algeria, USA, Canada, Nigeria, Australia) had much lower (i.e., better) rankings, an average of 50.8 on the HDI and 35 on the WHR. Thus, it appears that societies with unusually large over- or under-representation of left-handedness may pay a price for the lack of balance between flexible and rigid thinking styles.
In conclusion, we argue that classifying humans in terms of consistent- versus inconsistent-handedness is more consistent with behavioral, genetic, and evolutionary considerations than the traditional left-right classification scheme. Moreover, we argue that that the different cognitive styles of these handedness groups conveys an adaptive benefit to human society as a whole, with consistent-handers serving as stable, rigid "oaks," and inconsistent-handers serving as more flexible "willows."

\section{References}

Alipour, A., Aerab-Sheybani, K., \& Akhondy, N. (2012). Effects of handedness and depth of processing on the explicit and implicit memory. Procedia - Social \& Behavioral Sciences, 32, 29-33.

Amodio, D. M., Jost, J. T., Master, S. L., \& Yee, C. M. (2007). Neurocognitive correlates of liberalism and conservatism. Nature Neuroscience, 10, 1246-1247.

Annett, M. (2002). Handedness and brain asymmetry: the right shift theory. New York: Psychology Press.

Arning, L., Ocklenburg, S., Schulz, S., Ness, V., Gerding, W. M., Hengstler, J. G., ... \& Beste, C. (2013). PCSK6 VNTR polymorphism is associated with degree of handedness but not direction of handedness. PLoS One, 8, e67251.

Arning, L., Ocklenburg, S., Schulz, S., Ness, V., Gerding, W. M., Hengstler, J. G., ... \& Beste, C. (2015). Handedness and the X chromosome: the role of androgen receptor CAG-repeat length. Scientific Reports, 5. doi:10.1038/srep08325.

Barnett, K. J., \& Corballis, M. C. (2002). Ambidexterity and magical ideation. Laterality: Asymmetries of Body, Brain and Cognition, 7, 75-84.

Bowden, E. M., \& Jung-Beeman, M. (2003). Aha! - insight experience correlates with solution activation in the right hemisphere. Psychonomic Bulletin \& Review, 10, 730-737.

Bryson, F. M., Grimshaw, G. M., \& Wilson, M. S. (2009). The role of intellectual openness in the relationship between hand preference and positive schizotypy. Brain and Cognition, 14, 441-456.

Caine, N. G., \& Mundy, N. I. (2000). Demonstration of a foraging advantage for trichromatic marmosets (Callithrix geoffroyi) dependent on food colour. Proceeding of the Royal Soceity of London B: Biological Sciences, 267, 439-444.

Caine, N. G., Surridge, A. K., \& Mundy, N. I. (2003). Dichromatic and trichromatic Callithrix geoffroyi differ in relative foraging ability for red-green color-camouflaged and non-camouflaged food. International Journal of Primatology, 24, 1163-1175.

Chagnon, N. A. (1988). Life histories, blood revenge, and warfare in a tribal population. Science, 239, 985-992.

Christman, S. D. (2013). Handedness and 'earedness': strong righthanders are less likely to prefer obscure musical genres. Psychology of Music, 41, 89-96.

Christman, S. (2014). Individual differences in personality as a function of degree of handedness: consistent-handers are less sensation seeking, more authoritarian, and more sensitive to disgust. Laterality: Asymmetries of Body, Brain and Cognition, 19, 354-367.

Christman, S. D., \& Butler, M. (2011). Mixed-handedness advantages in episodic memory obtained under conditions of intentional learning extend to incidental learning. Brain and Cognition, 77, 17-22.

Christman, S. D., \& Propper, R. E. (2001). Superior episodic memory is associated with interhemispheric processing. Neuropsychology, 15, 607-616.

Christman, S. D., Propper, R. E., \& Dion, A. (2004). Increased interhemispheric interaction is associated with decreased false memories in a 
verbal converging semantic associates paradigm. Brain and Cognition, 56, 313-319. doi:10.1016/j.bandc.2004.08.005.

Christman, S. D., Propper, R. E., \& Brown, T. J. (2006). Increased interhemispheric interaction is associated with earlier offset of childhood amnesia. Neuropsychology, 20, 336.

Christman, S. D., Bentle, M., \& Niebauer, C. L. (2007). Handedness differences in body image distortion and eating disorder symptomatology. International Journal of Eating Disorders, 40, 247-256.

Christman, S. D., Henning, B. R., Geers, A. L., Propper, R. E., \& Niebauer, C. L. (2008). Mixed-handed persons are more easily persuaded and are more gullible: interhemispheric interaction and belief updating. Laterality, 13, 403-426.

Christman, S. D., Sontam, V., \& Jasper, J. D. (2009). Individual differences in ambiguous figure perception: degree of handedness and interhemispheric interaction. Perception, 38, 1183-1198.

Christman, S. D., Prichard, E. C., \& Corser, R. (2015). Factor analysis of the Edinburgh Handedness Inventory: inconsistent handedness yields a two-factor solution. Brain and Cognition, 98, 82-86.

Chu, O., Abeare, C. A., \& Bondy, M. A. (2012). Inconsistent vs. consistent right handers' performance on an episodic memory task: evidence from the California Verbal Learning Test. Laterality: Asymmetries of the Body, Brain \& Cognition, 17, 306-331.

Cole, E. F., \& Quinn, J. L. (2014). Shy birds play it safe: personality in captivity predicts risk responsiveness during reproduction in the wild. Biology Letters, 10, 20140178.

Darwin, C. (1875). The variation of animals and plants under domestication (2nd ed., revised). London: John Murray. (Original publication, 1868; reprinted in The Works of Charles Darwin. Vol. 19: Variations of animals and plants under domestication, by P. H. Barrett \& R. B. Freeman, Eds., 1988, New York: New York Univ. Press).

Davidson, R. J. (2000). The functional neuroanatomy of affective style. In R. D. Lane \& L. Nadel (Eds.), Cognitive neuroscience of emotion (pp. 371-388). New York: Oxford University Press.

Davidson, T., \& Tremblay, F. (2013). Hemispheric differences in corticospinal excitability and in transcallosal inhibition in relation to degree of handedness. PLoS One, 8(7), e70286.

Edlin, J. M., Carris, E. K., \& Lyle, K. B. (2013). Memory for hand-use depends on consistency of handedness. Frontiers in Human Neuroscience, 7 .

Edlin, J. M., Leppanen, M. L., Fain, R. J., Hackländer, R. P., HanaverTorrez, S. D., \& Lyle, K. B. (2015). On the use (and misuse?) of the Edinburgh Handedness Inventory. Brain and Cognition, 94, 44-51.

Evans, E. M. (2000). The emergence of beliefs about the origins of species in school-age children. Merrill-Palmer Quarterly, 46, 19-52.

Frayer, D. W., Lozano, M., de Castro, J. M., Carbonell, E., Arsuaga, J. L., Radovčić, J., Fiore, I., \& Bondioli, L. (2012). More than 500, 000 years of right-handedness in Europe. Laterality, 17, 51-69.

Grimshaw, G. M., \& Wilson, M. S. (2013). A sinister plot? Facts, beliefs, and stereotypes about the left-handed personality. Laterality, 18, $135-151$.

Habib, R., Nyberg, L., \& Tulving, E. (2003). Hemispheric asymmetries of memory: the HERA model revisited. Trends in Cognitive Sciences, 7, 241-245

Hampson, E., \& Sankar, J. S. (2012). Hand preference in humans is associated with testosterone levels and androgen receptor gene polymorphism. Neuropsychologia, 50, 2018-2025.

Hardie, S. M., \& Wright, L. (2014). Differences between left-and righthanders in approach/avoidance motivation: influence of consistency of handedness measures. Frontiers in Psychology, 5. doi:10.3389/fpsyg.2014.00134.

Harris, L. J. (2000). On the evolution of handedness: a speculative analysis of Darwin's views and a review of early studies of handedness in the 'the nearest allies of man'. Brain and Language, 73, 132-188.

Hecht, D. (2010). Depression and the hyperactive right-hemisphere. Neuroscience Research, 68, 77-87.
Helliwell, J., Layard, R., \& Sachs, J. (2015). World Happiness Report. New York: Columbia University Earth Institute.

Jasper, J. D., \& Christman, S. D. (2005). A neuropsychological dimension for anchoring effects. Journal of Behavioral Decision Making, 18, 343-369.

Jasper, J. D., Barry, K., \& Christman, S. D. (2008). Individual differences in counterfactual production. Personality and Individual Differences, 45, 488-492.

Jasper, J. D., Prothero, M., \& Christman, S. D. (2009). I'm not sexist!!! Cognitive dissonance and the differing cries of mixed- and stronghanders. Personality and Individual Differences, 47, 268-272.

Kaiser, D. (2011). How the hippies saved physics: science, counterculture, and the quantum revival. WW Norton \& Company.

Kanai, R., Feilden, T., Firth, C., \& Rees, G. (2011). Political orientations are correlated with brain structure in young adults. Current Biology, $21,677-680$

Kuhnlein, H. V., \& Receveur, O. (1996). Dietary changes and traditional food systems of indigenous peoples. Annual Review of Nutrition, 16, 417-442.

Leach, E. L., Prefontaine, G., Hurd, P. L., \& Crespi, B. J. (2014). The imprinted gene LRRTM1 mediates schizotypy and handedness in a nonclinical population. Journal of Human Genetics, 59, 332-336.

Lizot, J. (1994). On warfare: an answer to N. A. Chagnon. American Ethnologist, 21, 845-862.

Llauren, V., Raymond, M., \& Faurie, C. (2009). Why are some people left-handed? An evolutionary perspective. Philosophical Transactions of the Royal Society of London. Series B: Biological Science, 364, 881-894.

Luders, E., Cherbuin, N., Thompson, P. M., Gutman, B., Anstey, K. J., Sachdev, P., \& Toga, A. W. (2010). When more is less: associations between corpus callosum size and handedness lateralization. NeuroImage, 52, 43-49.

Lyle, K. B., \& Grillo, M. C. (2014). Consistent-handed individuals are more authoritarian. Laterality: Asymmetries of Body, Brain and Cognition, 19, 146-163.

Lyle, K. B., McCabe, D. P., \& Roediger, H. L., III. (2008). Handedness is related to memory via hemispheric interaction: evidence from paired associate recall and source memory tasks. Neuropsychology, $22,523$.

Lyle, K. B., Hanaver-Torrez, S. D., Hackländer, R. P., \& Edlin, J. M. (2012). Consistency of handedness, regardless of direction, predicts baseline memory accuracy and potential for memory enhancement. Journal of Experimental Psychology. Learning, Memory, and Cognition, 38, 187.

Lyle, K. B., Chapman, L. K., \& Hatton, J. M. (2013). Is handedness related to anxiety? New answers to an old question. Laterality: Asymmetries of Body, Brain and Cognition, 18, 520-535.

Mallon, T. (2016). A view from the fringe: the John Birch Society and the rise of the radical right. Retrieved from http:/www.newyorker.com/ magazine/2016/01/11/a-view-from-the-fringe.

McDowell, A., Felton, A., Vazquez, D., \& Chiarello, C. (2015). Neurostructural correlates of consistent and weak handedness. Laterality: Asymmetries of Body, Brain and Cognition [pre-print epub].

McGilchrist, I. (2009). The master and his emissary: the divided brain and the making of the western world. Yale University Press.

McManus, I. C. (1980). Handedness in twins: a critical review. Neuropsychologia, 18, 347-355.

McManus, I. C. (1991). The inheritance of left-handedness. In G. R. Bock \& J. Marsh (Eds.), Ciha Foundation Symposium 162: biological asymmetry and handedness (pp. 251-281). Chichester: Wiley.

McManus, I. C. (2009). The history and geography of human handedness. In I. E. C. Sommer \& R. S. Kahn (Eds.), Language lateralization and psychosis (pp. 37-57). Cambridge: Cambridge University Press.

McManus, I. C., Davison, A., \& Armour, J. A. (2013). Multilocus genetic models of handedness closely resemble single-locus models in 
explaining family data and are compatible with genome-wide association studies. Annals of the New York Academy of Sciences, 1288, $48-58$.

Niebauer, C. L., Aselage, J., \& Schutte, C. (2002). Hemispheric interaction and consciousness: degree of handedness predicts the intensity of a sensory illusion. Laterality: Asymmetries of Body, Brain and Cognition, 7, 85-96.

Niebauer, C., Christman, S., Reid, S., \& Garvey, K. (2004). Interhemispheric interaction and beliefs on our origin: degree of handedness predicts beliefs in creationism versus evolution. Laterality: Asymmetries of Body, Brain and Cognition, 9, 433-447.

Oldfield, R. (1971). The assessment and analysis of handedness: The Edinburgh inventory. Neuropsychologia, 9(1), 97-113. doi:10. 1016/0028-3932(71)90067-4

Parker, A., \& Dagnall, N. (2010). Effects of handedness and saccadic bilateral eye movements on components of autobiographical recollection. Brain and Cognition, 73, 93-101.

Perelle, I. B., \& Ehrman, L. (1994). An international study of human handedness: the data. Behavior Genetics, 24, 217-227.

Prichard, E., Propper, R. E., \& Christman, S. D. (2013). Degree of handedness, but not direction, is a systematic predictor of cognitive performance. Frontiers in Psychology, 4, 3-6.

Propper, R. E., \& Christman, S. D. (2002). Individual differences in recognition memory: strength of handedness and know/remember judgments. Brain and Cognition, 48, 251.

Propper, R. E., \& Christman, S. D. (2004). Mixed-versus strong righthandedness is associated with biases towards "remember" versus "know" judgments in recognition memory: role of interhemispheric interaction. Memory, 12, 707-714.

Propper, R. E., Christman, S. D., \& Phaneuf, K. A. (2005). A mixedhanded advantage in episodic memory: a possible role of interhemispheric interaction. Memory \& Cognition, 33, 751-757.
Propper, R. E., Pierce, J., Geisler, M. W., Christman, S. D., \& Bellorado, N. (2012). Hemispheric asymmetry in frontal EEG: inconsistentright-handers are more right hemisphere active. Open Journal of Medical Psychology, 1, 86-90.

Ramachandran, V. S. (1995). Anosognosia in parietal lobe syndrome. Consciousness and Cognition, 4, 22-51.

Raymond, M., \& Pontier, D. (2004). Is there geographical variation in human handedness? Laterality, 9, 35-52.

Raymond, M., Pontier, D., Dufour, A. B., \& Moller, A. P. (1996). Frequency-dependent maintenance of left handedness in humans. Proceedings of the Royal Society of London B: Biological Sciences, 263, 1627-1633.

Shobe, E. R., Ross, N. M., \& Fleck, J. I. (2009). Influence of handedness and bilateral eye movements on creativity. Brain and Cognition, 71, 204-214.

Sontam, V., \& Christman, S. D. (2012). Semantic organization and handedness: mixed-handedness is associated with more diffuse activation of ambiguous word associates. Laterality, 17, 38-50.

Sontam, V., Christman, S. D., \& Jasper, J. D. (2009). Individual differences in semantic switching flexibility: effects of handedness. Journal of the International Neuropsychological Society, 15, 1023-1027.

Taylor, P., Funk, C., \& Craighill, P. (2006). Are we happy yet? Retrieved November 15, 2014, from http://pewresearch.org/files/old-assets/ social/pdf/AreWeHappyYet.pdf.

United Nations Development Programme. (2014). Human Development Report 2014. New York: Oxford University Press.

Westfall, J., Jasper, J. D., \& Christman, S. D. (2012). Inaction inertia, the sunk cost effect, and handedness: avoiding the losses of past decisions. Brain and Cognition, 80, 192-200. 